\title{
Development of a SMA-Based, Slat-Gap Filler for Airframe Noise Reduction
}

\author{
Travis L. Turner ${ }^{1}$ \\ NASA Langley Research Center, Hampton, VA 23681 \\ and \\ David L. Long ${ }^{2}$ \\ Analytical Mechanics Associates, Hampton, VA 23666
}

\begin{abstract}
Noise produced by unsteady flow around aircraft structures, termed airframe noise, is an important source of aircraft noise during the approach and landing phases of flight. Conventional leading-edge-slat devices for high lift on typical transport aircraft are a prominent source of airframe noise. Many concepts for slat noise reduction have been investigated. Slat-cove fillers have emerged as an attractive solution, but they maintain the gap flow, leaving some noise production mechanisms unabated, and thus represent a nonoptimal solution. Drooped-leading-edge (DLE) concepts have been proposed as "optimal" because the gap flow is eliminated. The deployed leading edge device is not distinct and separate from the main wing in DLE concepts and the high-lift performance suffers at high angles of attack $(\alpha)$ as a consequence. Elusive high- $\alpha$ performance and excessive weight penalty have stymied DLE development. The fact that high-lift performance of DLE systems is only affected at high $\alpha$ suggests another concept that simultaneously achieves the high-lift of the baseline airfoil and the noise reduction of DLE concepts. The concept involves utilizing a conventional leading-edge slat device and a deformable structure that is deployed from the leading edge of the main wing and closes the gap between the slat and main wing, termed a slat-gap filler (SGF). The deployable structure consists of a portion of the skin of the main wing and it is driven in conjunction with the slat during deployment and retraction. Benchtop models have been developed to assess the feasibility and to study important parameters. Computational models have assisted in the bench-top model design and provided valuable insight in the parameter space as well as the feasibility.
\end{abstract}

\section{Nomenclature}

$\begin{array}{ll}\text { A } & =\text { planform area } \\ C_{L} & =\text { lift coefficient } \\ C_{p} & =\text { pressure coefficient } \\ \text { Cusp } & =\text { lower trailing edge of slat } \\ \text { DLE } & =\text { drooped leading edge } \\ L & =\text { aerodynamic lift } \\ \text { OML } & =\text { outer mold line } \\ \text { RoFC } & =\text { region of fixed curvature } \\ \text { SCF } & =\text { slat-cove filler } \\ \text { SGF } & =\text { slat-gap filler } \\ \text { SMA } & =\text { shape memory alloy } \\ \alpha & =\text { angle of attack } \\ \rho & =\text { mass density } \\ \sigma^{\text {Af }}, \sigma^{\text {As }} & =\text { austenite finish/start critical stress }\end{array}$

\footnotetext{
${ }^{1}$ Research Engineer, Structural Acoustics Branch, 2 N Dryden Street/Mail Stop 463, AIAA Senior Member

${ }^{2}$ Designer III, TEAMS2 - Structural Dynamics Branch, 4B W Taylor Street/Mail Stop 230
} 
$\begin{aligned} \sigma^{M f}, \sigma^{M s} & =\text { martensite finish/start critical stress } \\ v & =\text { fluid velocity }\end{aligned}$

\section{Introduction}

$\mathrm{H}$ IGH-lift systems for transport aircraft typically comprise a leading-edge slat and a trailing-edge flap that are designed to improve lift and stall characteristics at the high angles of attack $(\alpha)$ and low speeds required for landing. The leading and trailing edge devices are usually deployed away from the main wing, i.e., separated, in the high-lift configuration. These multi-element airfoil systems increase the effective chord and camber of the wing when deployed, but the main effect of the multi-element arrangement is to generate a much larger pressure difference between the upper and lower surfaces than would be possible with a single airfoil element. The multiple airfoil elements nest tightly together in the cruise configuration to minimize drag. In current practice, the leading edge of each element, after the foremost, fits into a cove in the aft lower surface of the preceding element. However, deployed high-lift systems present many geometric discontinuities, such as cavities, gaps and edges, to the flow. These geometric discontinuities produce unsteady aerodynamics that is the source of significant aeroacoustic noise, termed airframe noise.

A schematic representation of the flow field in the vicinity of a deployed, leading-edge-slat device is shown in Figure $1^{1}$. The flow splits at the stagnation point on the slat, indicated by numeral 3 in Figure 1, and the flow progressing on the lower surface separates from the slat at the cusp and forms a shear layer that reattaches in the top of the slat cove, thereby bounding a vortical recirculation region in the cove. These flow features, and their interaction with the structure, support many unsteady phenomena that are sources for radiated acoustic noise $e^{2-6}$. It is highly desirable to develop technologies that reduce slat noise without compromising cruise efficiency or the lift and stall characteristics at approach and landing.

Concepts that have been studied for reducing slat noise include brushes ${ }^{1,7}$, an extended blade seal ${ }^{8}$, serrated trailing edges, slat-cove fillers (SCFs) ${ }^{7,9-13}$ and drooped leading edges (DLEs) ${ }^{14-19}$. Brushes applied at the slat cusp and trailing edge, intended to damp the fluctuating pressures there, increase drag at cruise and provide only a modest noise benefit. Serrated cusp

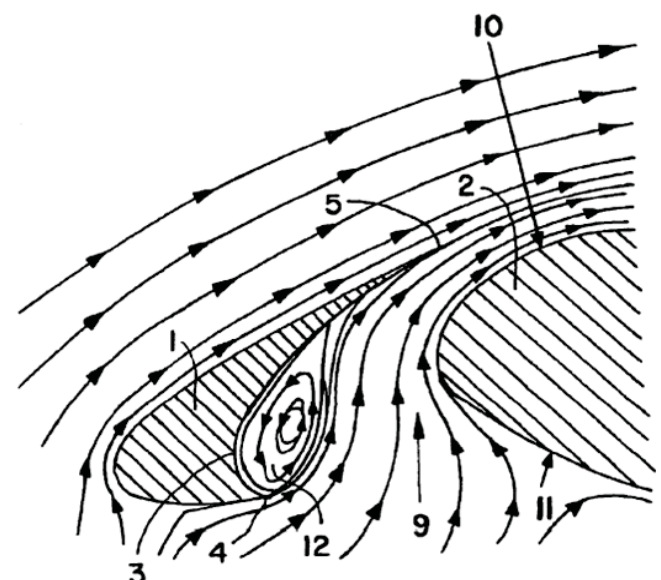

Figure 1. Flow streamlines in the slat region of a conventional airfoil, from U.S. Patent No. $6,789,769^{1}$.

and trailing edges were investigated as an alternative to brushes in an attempt at avoiding a cruise drag penalty. An extended blade seal, i.e., a thin, strategically-contoured extension to the slat cusp, was studied as a means of guiding the gap flow while leaving the slat, main wing and their stowed configuration relatively unaltered. Neither a serrated edge nor an extended blade seal resulted in significant noise reduction in a wind tunnel test ${ }^{10}$. The SCF concept has been shown, both experimentally ${ }^{10,11}$ and computationally ${ }^{12,13}$ to significantly reduce slat noise. Recent work has been done to demonstrate the feasibility of developing an autonomous (passive) SCF device ${ }^{20,21}$.

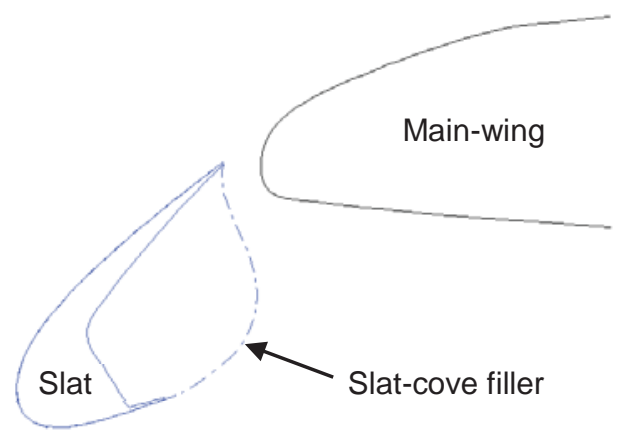

Figure 2. Schematic of a SCF on a representative airfoil.

Although the SCF concept is attractive both in terms of performance and implementation, the noise benefit of SCF systems is limited by the fact that the flow between the deployed slat and the main wing is maintained, along with some of the noise production mechanisms. It is desirable, from an aeroacoustic noise perspective, to eliminate the flow between the slat and main wing to minimize the noise production mechanisms and maximize the noise benefit. DLE concepts have thus been proposed and studied because the gap flow is eliminated in those cases. However, DLE concepts suffer significantly in high- $\alpha$ and $\mathrm{C}_{\mathrm{Lmax}}$ performance and no approach has been devised to remedy those shortcomings.

The main objective of the work presented in this study was to develop a noise-treatment-device concept for the leading-edge slat that achieves the noise reduction potential of DLE concepts while either improving or resulting in negligible detrimental effect on the high-lift aerodynamics at any angle of attack. Secondary objectives included studying the parametric design space of such a device and demonstrating the feasibility 
of practical implementation. Physical models were developed in parallel with development of computation models, which were used to guide design. Descriptions of the models and interpretation of results from them will be presented.

\section{Background}

A schematic of a desirable SCF configuration is shown in Figure 2 for reference. As mentioned previously, the flow between the slat and main wing in the deployed configuration is maintained but guided strategically to minimize the unsteadiness in the flow and thus the radiated noise. The SCF profile shown in Figure 2 is prescribed by the total pressure field between the slat and main wing and has been shown to produce the maximum noise reduction of concepts in the SCF class. In contrast, a notional schematic of DLE concepts, i.e., airfoil in the high-lift configuration with the main wing and the leading-edge slat remaining contiguous, is shown in Figure 3.

Typical DLE systems involve a leading edge that extends forward and/or rotates down, much like a traditional leading-edge slat. However, the leading edge remains contiguous with the wing in DLE systems via a compliant

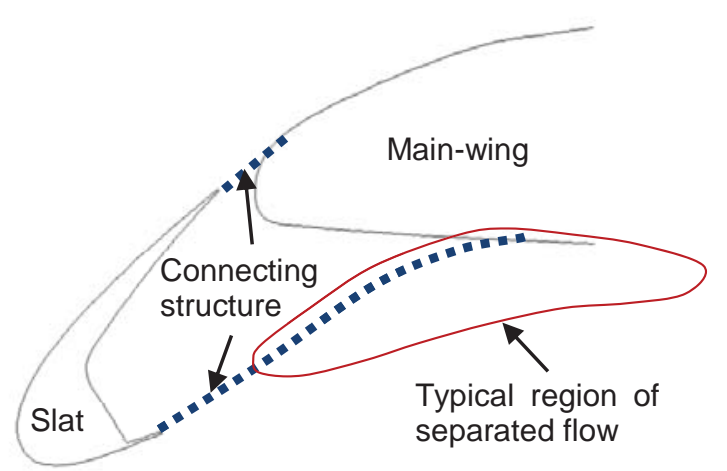

Figure 3. Notional schematic of a gapless highlift system or a drooped leading edge. and/or mechanized structural system. Excellent noise reduction performance has been reported for DLE systems, significantly exceeding that of SCF systems, because more of the noise production mechanisms are mitigated. However, DLE systems typically represent a significant weight addition because of the extensive added structure and accompanying actuation requirements. More importantly, DLE systems cannot achieve the required lift and stall performance at high $\alpha$ because they negate the advantage of a multi-element, high-lift system described in the previous

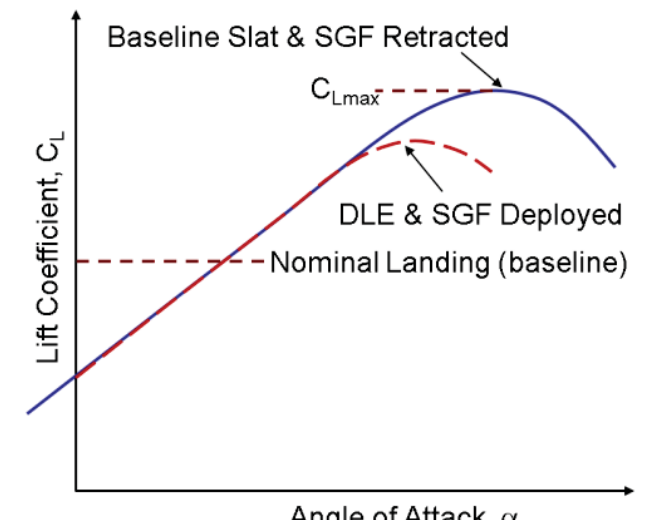

Angle of Attack, $\alpha$

Figure 4. Representative plot of $C_{L}$ vs. $\alpha$. section. This effect is illustrated in the representative plot of lift coefficient versus $\alpha$ in Figure 4.

The maximum lift coefficient $\mathrm{C}_{\mathrm{Lmax}}$ is measured by varying the $\alpha$ of the fully-deployed airfoil in a wind tunnel under Reynolds number and airspeed conditions representative of landing. The stall speed, speed at which an increase in $\alpha$ does not increase lift, can be determined from $\mathrm{C}_{\mathrm{Lmax}}$ and the weight of the aircraft via the equation $L=\rho v^{2} A C_{L} / 2$, where $\rho, v$ and $A$ are the fluid density, airspeed and planform area of the airfoil, respectively. FAA regulation (FAR 25) dictates a landing speed of no less than 1.3 times the stall speed, i.e., $v_{\text {land }}=1.3 v_{\text {sall }}$. The corresponding lift coefficient requirement at landing can, thus, be determined from the equation $2 L / \rho A C_{L}=3.38 \mathrm{~L} / \rho A C_{L \max }$ or $C_{L} \sim 0.6 C_{L \max }$.

It can be seen that DLE systems exhibit a significant shortfall on $\mathrm{C}_{\mathrm{Lmax}}$ and the stall angle in comparison to the baseline airfoil. This deficit leads to a requirement for recovering $\mathrm{C}_{\mathrm{Lmax}}$ by some auxiliary means. Active flow control and exaggerated extension/rotation of the leading edge have been proposed to improve the high-lift performance of DLE systems ${ }^{22,23}$. Both of these approaches involve substantial weight penalty, complex and difficult implementation and/or poor low- $\alpha$ lift performance. Alternatively, accepting the deficit in $\mathrm{C}_{\mathrm{Lmax}}$ leads to infeasible landing conditions in terms of airspeed and/or $\alpha$. The deficit could also be accommodated by a reduction in aircraft weight and/or commensurate increase in wing area to avoid the infeasible landing conditions. None of these alternatives for regaining the high- $\alpha$ lift performance and $C_{L m a x}$ are typically considered acceptable.

Another alternative becomes clear when the possibility of closing only the top of the slat-wing gap is considered, depicted schematically in Figure 5 and termed the slat-gap filler (SGF) concept. The SGF concept has the advantage of imposing little added structure and a correspondingly small weight penalty to the airframe relative to DLE concepts. What is perhaps less obvious is that the aerodynamics of the two configurations (SGF and DLE) are very similar when the SGF is deployed and the gap is closed, as indicated in Figure 4. Closing the narrow gap at the trailing edge of the

American Institute of Aeronautics and Astronautics 
slat eliminates the gap flow and provides a continuous surface for the flow on the low-pressure (top) surface of the airfoil. The large cavity presented to the flow on the high-pressure (bottom) surface of the airfoil is not of significant consequence because the freestream flow is directed aft (downstream) of the stagnation point on the main wing, also indicated in Figure 5. The resulting region of separated flow, bounding a region of vortical recirculation between the slat cusp and the stagnation point on the main wing, is similar to an analogous region of separated flow exhibited by DLE systems as a function of $\alpha$, indicated in Figure 3 by the red oval. Thus, the structural configuration between the slat and main wing on the bottom of the airfoil is unimportant and the aerodynamic and aeroacoustic performance of the two systems (DLE and SGF) are similar when the gap is closed.

The key advantage of the SGF concept, however, is that autonomous and failsafe deployment and retraction is conceivable. The importance of this advantage will be made clear in the following discussion. The typical range of lift and $\alpha$ encountered during the approach and landing phases of the flight envelope of a commercial transport aircraft are in the vicinity of the nominal landing condition indicated in Figure 4 . The greater lift at higher $\alpha, C_{L \max }$ and the stall angle are all characteristics of atypical or emergency flight conditions that the aircraft may never encounter. Thus, a concept that can selectively prevent the gap flow to achieve maximum noise reduction but permit the gap flow in atypical or emergency conditions is ideal. The SGF concept represents a novel and unique approach to achieve the gap-ondemand objective with low weight penalty. The SGF reverts to the baseline high-lift configuration when the SGF is retracted. Thus, the retracted SGF achieves the lift $\left(C_{L}\right.$ vs. $\left.\alpha, C_{L \max }\right)$ and stall

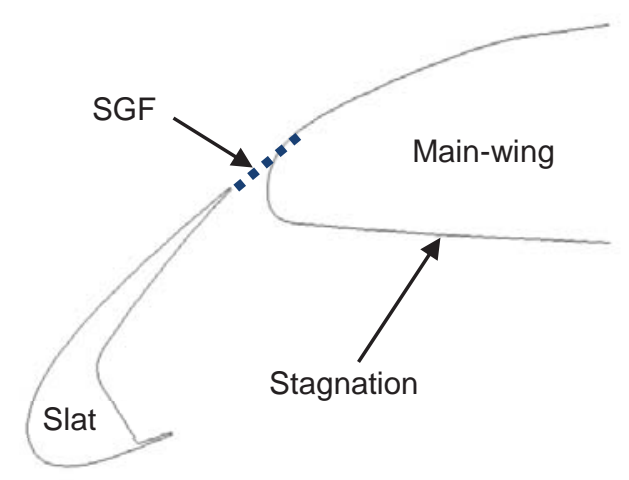

Figure 5. Notional simplified gapless highlift system; the SGF. characteristics of the baseline airfoil, as indicated in Figure 4. Specifically, the SGF concept simultaneously provides the maximum noise reduction possible and lift equivalent to the baseline airfoil under typical operating conditions, i.e., with the gap closed. The gap is opened in emergency conditions to achieve optimized lift performance at the expense of increased noise in an emergency when noise is not a concern. The remainder of this document will describe work done to develop a SGF concept that is feasible for physical implementation.

\section{Requirements and Constraints}

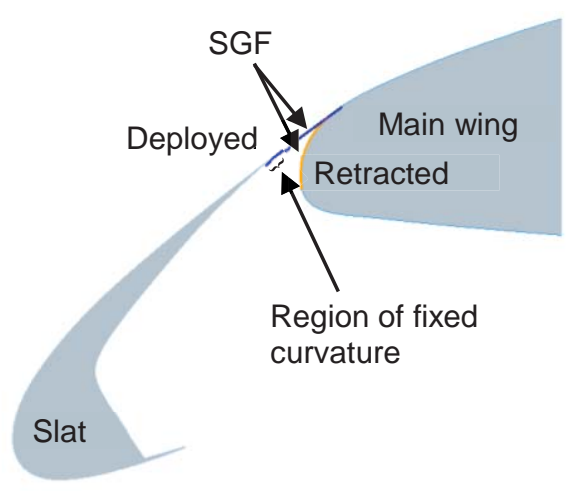

Figure 6. Schematic of the main-wing skin segment required to close the gap.

Several design considerations affected development of the SGF concept. The SGF structure is required to deploy automatically and in conjunction with the slat such that the slat gap is never opened under normal operating conditions. The SGF structure must also retract automatically in conjunction with the slat or otherwise stow within the main wing and/or slat volume available in the cruise configuration. It must sustain the aerodynamic load imposed upon it in the normal operating condition (SGF deployed and the slat gap closed) and in the emergency, maximum-lift condition (SGF retracted and slat gap open). The SGF structure must transition between the deployed and retracted configurations autonomously, i.e., without pilot input, and at a rate that exceeds the pitch and engine spool-up rates encountered in emergency conditions. Achievement of these conditions ensures that the lift performance is unchanged by the presence of the SGF. As mentioned previously, it is also desirable to minimize added weight and complexity.

Many deformable and/or mechanized means of closing the gap between the slat trailing edge and the main wing were considered. The approach that best met the design constraints and objectives involved utilizing a portion of the skin on the leading edge of the main wing as a deformable, reconfigurable structure. The graphic shown in Figure 6 is a schematic of the concept that makes use of the modern-transport airfoil coordinates shown in Figure 2, Figure 3 and Figure 5. The physical and computational models shown in this study were motivated by this schematic that represented spanwise uniform geometry, analogous to previous slat-cove filler development work, at $75 \%$ scale for which the chordwise length of the SGF was approximately 4.75 inches. The geometry also consisted of a span-wise 
slice, 0.75 inches thick (in span) with a spanwise uniform cross section. Other salient features of the configuration shown are as follows.

The SGF was envisioned to be attached and form a flexure joint where it joins the main wing, but not affixed to the main wing elsewhere and thus unable to support wing loads. The SGF was also envisioned to be as thin as possible with the driving factor on thickness being the ability to sustain its local aerodynamic loads. Therefore, the SGF was envisioned to "leaf over" skin structure that occupies the same wing acreage but that is fully affixed to the wing substructure and is thus the "stressed skin" that supports the wing loads. A lap joint with the SGF beneath the trailing edge of the slat was incorporated to prevent any possibility of misalignment and binding in the deployed configuration. Actuation of the SGF by a control force applied near the free end was also envisioned. It was required that the free end of the SGF butt tightly against the adjacent skin affixed to the main wing just below the SGF in order to produce a smooth aerodynamic surface on the leading edge of the main wing in the emergency configuration, i.e., with the slat deployed and the SGF retracted. Thus, the curvature of the deployed SGF in the vicinity of the free end (near the slat trailing edge) is fixed, as indicated in Figure 6, and matches the curvature required for the retracted configuration. This region of fixed curvature (RoFC) could be maintained by a spanwise stringer. The stringer could also serve the functions of attaching an actuator to the SGF and bridging the actuation authority between discrete actuators. The remainder of the deployed SGF shown in Figure 6, aft of the fixed-curvature segment, has a constant slope that is a continuation of the outer mold line (OML) tangent at the slat trailing edge and extends to the tangent point on the main wing. Note that although the retracted shape of the SGF must match the as-designed OML of the main wing, the deployed configuration shown in Figure 6 is not optimized and is intended only for illustration. Specific design aspects would likely vary with airframe application. Note also that the chordwise extent of the SGF structure required to close the slat gap is well forward of the stagnation point on the main wing, regardless of $\alpha$.

At least two structural options are possible to achieve both configurations and movement between them; one that has restoring force driving it to the deployed configuration and one that has restoring force driving it to the retracted configuration. The simplest, albeit perhaps suboptimal, implementation of either of these two options consists of a SGF that is stress free in the deployed or retracted configuration, respectively. There is a trade-off between these two design options in terms of complexity and actuation requirement. The aerodynamic load and restoring force combine for the stress-free-deployed (SFD) case and they oppose one another for the stress-free-retracted (SFR) case, suggesting that the SFD case would require more actuator authority to retract than the SFR case would to deploy. What is perhaps less obvious is that the SFD case is simpler to implement in terms of achieving a specific deployed shape because it naturally strives for the desired configuration to relieve stress. Additional provisions (e.g., variable thickness) or constraints (e.g., chordwise distributed stays that become taught sequentially from root to tip with SGF deployment) are required for the SFR case to achieve a specific deployed shape such as that shown in Figure 6 because a majority of the bending would occur at the root end without such provisions/constraints. Note that if the deployed shape requirement were relaxed to allow whatever shape the SFR achieved upon deployment, the actuator requirement could be significantly reduced. Both the SFD and SFR structural options will be explored in the subsequent analyses and these observations will be revisited in discussion of the results.

\section{Bench-Top Model}

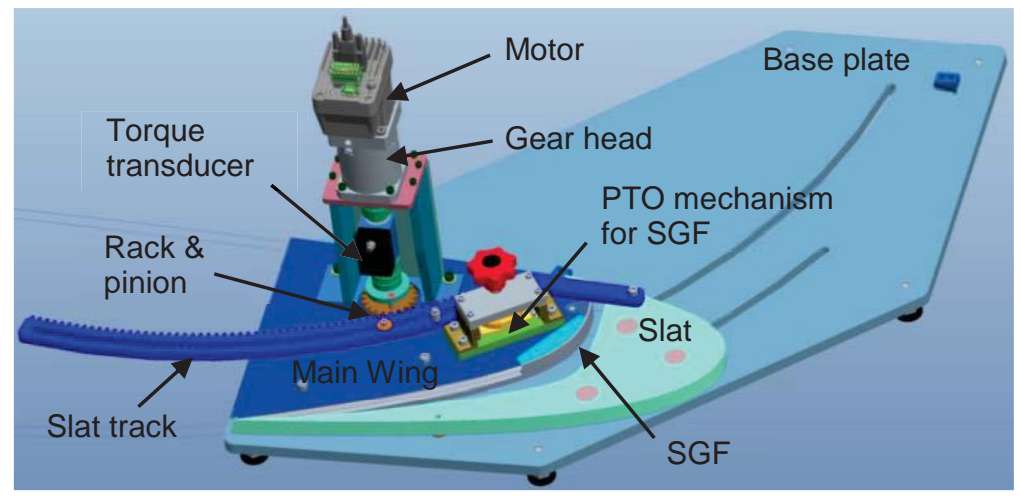

Figure 7. CAD model of bench-top apparatus showing assembly parts in retracted configuration.
Previous work was done to study the feasibility and to perform a parametric study of a slat-cove-filler concept on a bench-top model consisting of a thin, spanwise-uniform slice of an airfoil motivated by Figure $2^{20}$. An analogous bench-top model was developed for feasibility and parametric study of SGF concepts. A CAD model of the bench-top apparatus is shown in the retracted configuration in Figure 7. The apparatus consists of main-wing and slat components arranged on a base plate such that slots guide the slat motion according to an appropriate slat articulation schedule.

A simplified mock-up of a modern slat actuation system, consisting of an electric motor, gear reducer, rack and pinion 
gearing and a slat track, was devised to actuate the slat. It was clear from the requirements and constraints that articulation of the SGF should be scheduled with that of the slat. It was also clearly undesirable to introduce a supplementary actuation system for the SGF. Therefore, a means of coupling the SGF actuation to the slat actuator was devised via a power-take-off (PTO) mechanism, which involved an intermittent (Geneva) gear and provisions for "emergency" release, to direct some of the slat actuator authority to the SGF. The PTO mechanism was also designed to apply force to the SGF in the direction normal to the OML throughout the range of motion. This design attribute will be discussed in more detail in the next section. A

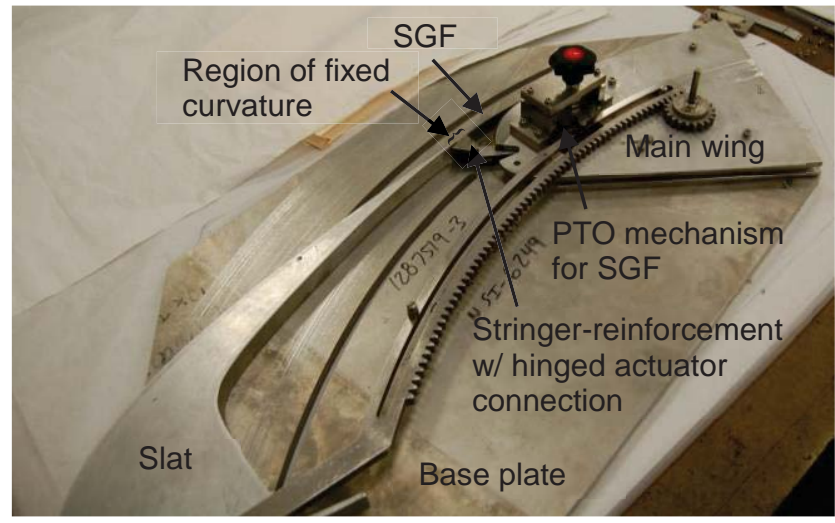

Figure 8. Bench-top apparatus in the deployed config. picture of the bench-top apparatus at an intermediate stage of assembly, excluding the motor and gearbox for clarity, is shown in the deployed configuration in Figure 8. Note that the design shown is not optimized and is meant to be an idealized representation of potential flight hardware.

Estimates of deformation required to reconfigure the SGF between the retracted and deployed configurations for the airframe shape in Figure 6 were on the order of 1\%, based on changes in curvature. This strain level was recognized as excessive for any conventional structural material and would result in permanent deformation or other failure. However, strains in this range and far greater, up to $7 \%$ depending on fatigue requirements, can be achieved by shape memory alloys (SMAs).

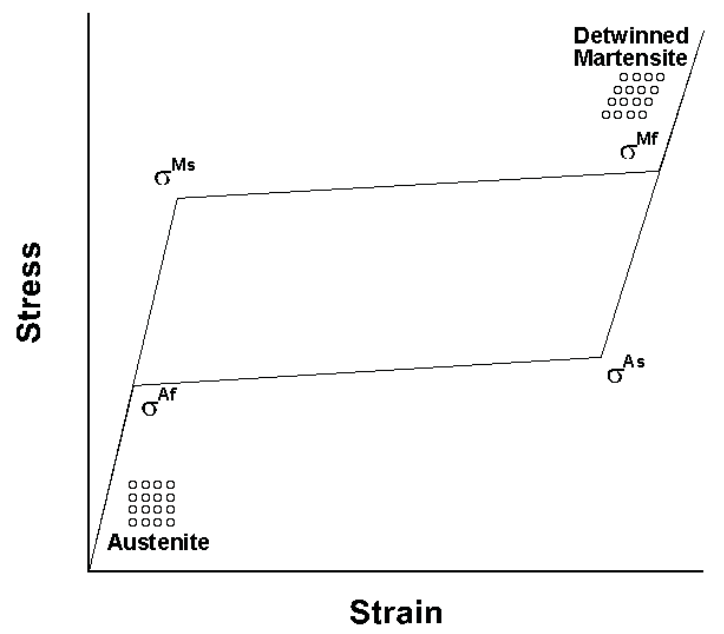

Figure 9. Schematic of superelasticity in SMAs, after Lagoudas $^{24}$.
A near-equiatomic alloy of Nickel and Titanium, called Nitinol, is the most common SMA and is currently the material of choice for this application. SMA materials exhibit a phase transformation between a high-temperature (typically cubic) microstructure called austenite and a lowtemperature (typically monoclinic, orthorhombic or tetragonal) microstructure called martensite in response to changes in temperature and applied stress. The material behavior being exploited in this application is pseudoelasticity (also called superelasticity), where the material is in the austenitic (high-temperature) phase under all operating temperatures and in the absence of stress and is transformed to martensite by application of stress. Unique features of this material behavior are shown in the idealized $\sigma-\varepsilon$ diagram in Figure $9^{24}$. It can be seen that the superelastic SMA material behaves like a conventional, linear-elastic material with increasing stress until a critical stress $\left(\sigma^{\mathrm{Ms}}\right.$, which is alloy-chemistry and temperature dependent) is reached. The microstructure begins transforming to martensite at the critical stress level and accommodates large deformation, up to $\sim 7 \%$ without incurring significant plasticity, by reorientation (detwinning) of the martensitic microstructure to variants that are consistent with the applied stress. The constitutive behavior reverts to linear-elastic response of detwinned martensite once transformation of the microstructure is complete. Removal of the applied stress is accompanied by recovery of elastic deformation in the detwinned martensite phase followed by the reverse transformation to austenite at another critical stress $\sigma^{\text {As }}$ that is characteristically lower than that for transforming to martensite. Continued reduction of the applied stress results in completion of the reverse transformation to austenite and complete recovery of all deformation, thereby returning the structure to its original configuration upon removal of all stress.

Note that implementation of the SGF approach via conventional materials could be possible on other airframe configurations with suitable geometric coordinates. Also, at $1 \%$ strain, the present implementation would likely only make use of the linear-elastic austenite and perhaps a small portion of the Martensite detwinning plateau. Nonetheless, unconventional materials are required simply because of the required strain and superelastic SMAs are the clear choice 
over alternatives due to their load-carrying capability, autonomous reconfigurability (i.e., transformation strain in regions of high stress) and environmental resistance.

Development of computational models was initiated in parallel with physical model development to aid in design and feasibility assessment. Although the eventual goal is to develop a computational model of the entire assembly to allow comparison of predicted drive torque and SGF deformation with experimental measurements, the computational models and results shown below are simplified to provide an assessment of force requirements and deformation levels and to begin exploration of design parameters, particularly with regard to two competing SGF implementation strategies (i.e., SFD vs. SFR). These topics will be described in detail in the next section.

\section{Computational Models}

\section{A. Stress-Free-Deployed Case}

An analysis was performed on the SFD SGF to determine the deflection of the structure due to a representative aerodynamic load. A finite element model of the deployed SGF was developed consisting of $1 / 8^{\text {th }}$-inch shell elements. Isotropic material properties corresponding to a nearequiatomic Nickel-Titanium alloy in the austenitic phase and a linear-elastic material model $(\mathrm{E}=7 \mathrm{Msi}, \mathrm{v}=0.33$ and $\left.\rho=6.03 \mathrm{e}-4 \mathrm{lbf} \mathrm{s} / \mathrm{in}^{4}\right)^{20}$ were chosen for this analysis. The linear-elastic constitutive model was suitable because small strain in the austenitic phase was anticipated. Boundary conditions were applied to model a riveted connection to the main wing and to model the stringer-reinforcement connecting an actuator to the RoFC at the other end. The latter BC consisted of a line of constrained $(\mathrm{u}, \mathrm{v}, \mathrm{w})$ nodes along the transverse centerline of the RoFC. The shell elements in the RoFC were assigned a higher modulus of elasticity of 70 Msi to model the stringer-reinforcement there. A CFD analysis was previously performed on the full airfoil represented by the coordinates in Figure 6. Computations were done with the slat gap open (reference configuration)

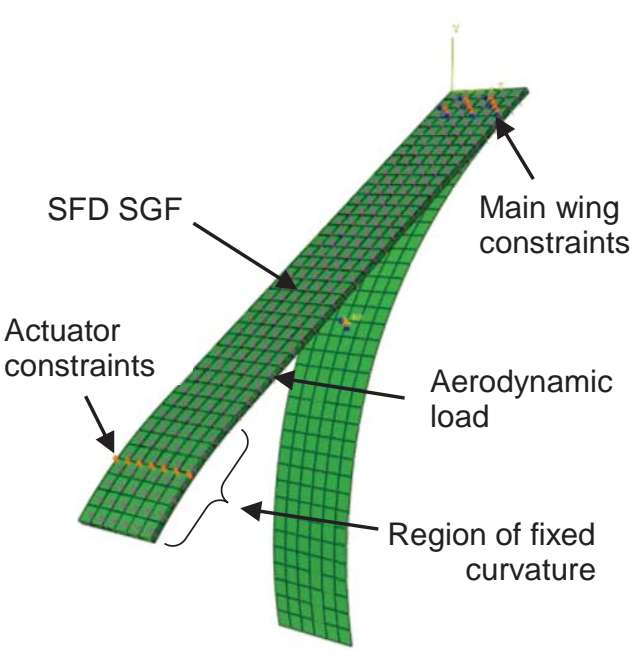

Figure 10. FEM for SFD SGF w/ aerodynamic load and BCs. and with the slat gap closed by the SGF. Flow conditions corresponding to the approach phase of flight ( $\mathrm{M}=0.2$ and $\alpha=6^{\circ}$ ) were imposed. An estimate of the average aerodynamic load acting on the deployed SGF, taken from the computed Cp distribution, was 1.1 psi. This pressure was uniformly distributed over the SGF to model the static aerodynamic load. The finite element model used for this analysis is shown in Figure 10.

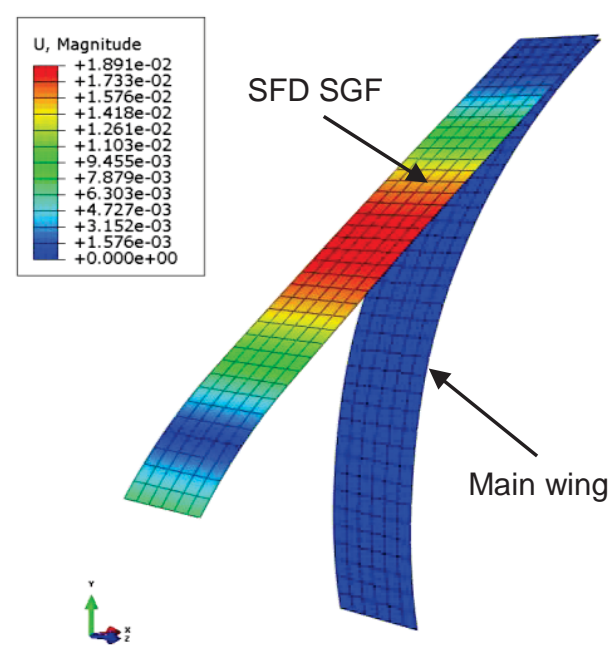

Figure 11. Displacement magnitude of 0.040 SFD SGF to 1.1 psi.

The maximum displacement magnitude for a SGF (skin) thickness of 0.040 inches was approximately 0.019 inches, as shown in Figure 11, which was negligible. Even at a 0.020-inch thickness, the maximum displacement magnitude was 0.033 inches, which was still quite small and considered compatible with maintaining attached flow at all nominal approach and landing conditions. The maximum strain incurred by the $0.040 / 0.020$ "-thick SFD SGF was approximately $432 / 560 \mu \varepsilon$ or $0.043 / 0.056 \%$, both of which met the small strain assumption above for the linear-elastic material assumption.

An additional analysis was performed on the SFD SGF to determine the actuator force required to draw the structure from the deployed to the retracted configuration and to determine the strain induced in the SGF as it was drawn around a frame used to enforce the retracted shape. The same finite element mesh was used along with the linear-elastic austenite material properties. Much larger

American Institute of Aeronautics and Astronautics 
strain was anticipated in this case, but $\sim 1 \%$ or less so linear-elastic material response in the austenite phase was still considered appropriate. The constraints representing a rivet connection to the main wing were left unchanged, but the actuator constraints were replaced by a concentrated forced in the center of the RoFC, as explained subsequently.

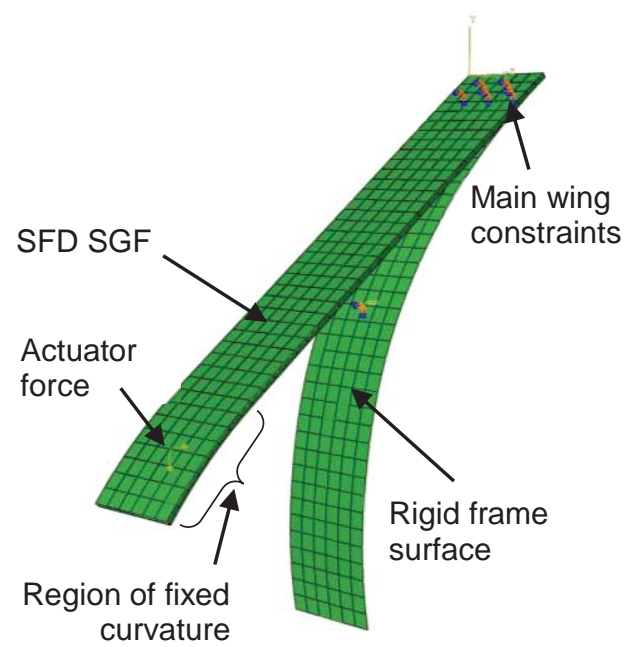

Figure 12. FEM for SFD SGF with actuator load and BCs.

An additional constraint imposed in this analysis was that the SGF structure should not be placed in tension or compression during its deployment or retraction. Any inplane force in the structure, tension or compression, is a waste of actuation authority, i.e., power. Furthermore, compression in the structure could also lead to buckling that could cause negative aerodynamic effects and/or structural failure. Thus, the actuator force was required to act normal to the SGF at the location of force application throughout articulation of the SGF. This was modeled by a concentrated force at the center of the RoFC, i.e., actuator attachment to the stringerreinforcement. The applied force was defined as a "follower" type that maintains an orientation that is normal to the structural surface at the point of force application. The shell elements in the RoFC were again assigned a higher modulus of elasticity of $70 \mathrm{Msi}$ to model the stringer-reinforcement there. The linear-elastic austenite shell elements were assigned a thickness of 0.040 inches. A rigid surface was defined to coincide with the inner (concave) surface of the SGF in the retracted configuration, as shown in the graphic of the finite element model in Figure 12. The rigid surface modeled the main-wing frame in a geometrically nonlinear (large displacement and rotation) contact analysis. The analysis was performed with increasing actuator force until the SGF was observed to make contact with the rigid frame over the entire length of the SGF. It was observed that the strain response in the SGF was dominated by the longitudinal in-plane strain. The logarithmic, longitudinal strain field on the outer (convex) surface of the 0.040 "-thick SGF at full retraction is shown in Figure 13. It can be seen that the maximum strain was approximately $7000 \mu \varepsilon$ or $0.7 \%$, which met the requirement for the linear-elastic material model.

The force needed to fully retract the SGF against the main-wing frame, ignoring the aerodynamic load, was found to be approximately $8 \mathrm{lbf}$ for the material properties and linear-elastic constitutive law used in the analysis. The actuator requirement would reduce by approximately a factor of 8 to $1 \mathrm{lbf}$ for a SGF with a thickness of 0.020 inches. An actuator force of approximately $2.2 \mathrm{lbf}$ would be required to overcome the resultant of the $1.1 \mathrm{psi}$ aerodynamic load in the fully-deployed configuration. As mentioned previously, the aerodynamic load acting on the deployed SGF would combine with the restoring force of the SFD SGF to seek the deployed configuration. The combination effect is indirect, however, as the aerodynamic load increases while the restoring force decreases with SFD SGF deployment. Although the combining effect would clearly lead to autonomous deployment with little or no actuator requirement, it would increase the actuator requirement for retraction, increase the bias needed to retract in anomalous or emergency conditions and it would represent a non-failsafe condition, i.e., bias required to ensure retraction in emergency or with actuator failure.
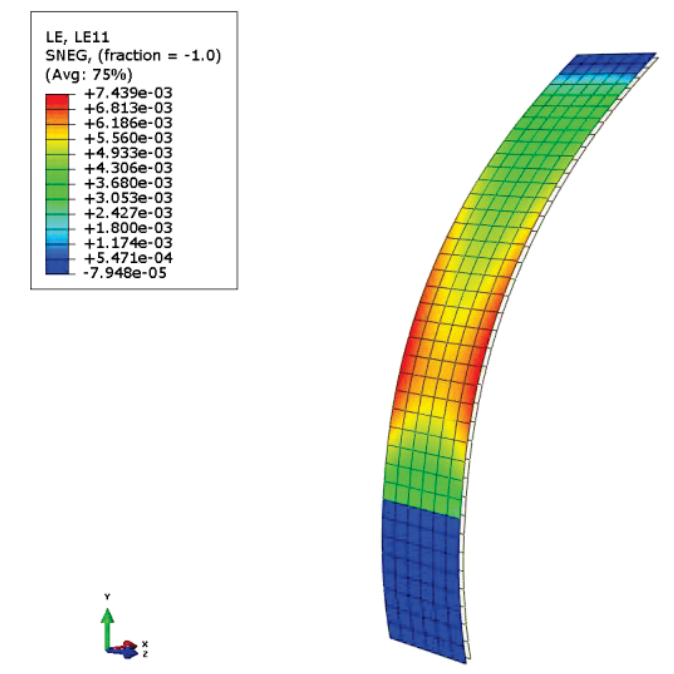

Figure 13. OML-surface strain due to SFD SGF retraction.

\section{B. Stress-Free-Retracted Case}

A similar analysis was performed to determine the actuator force required to deploy the SFR SGF to the specified deployed shape (see Figure 6) and to determine the resulting strain induced in the SGF. An analogous finite element model of the SFR SGF was developed consisting of $1 / 8^{\text {th }}$-inch shell elements. The same isotropic material properties

American Institute of Aeronautics and Astronautics 


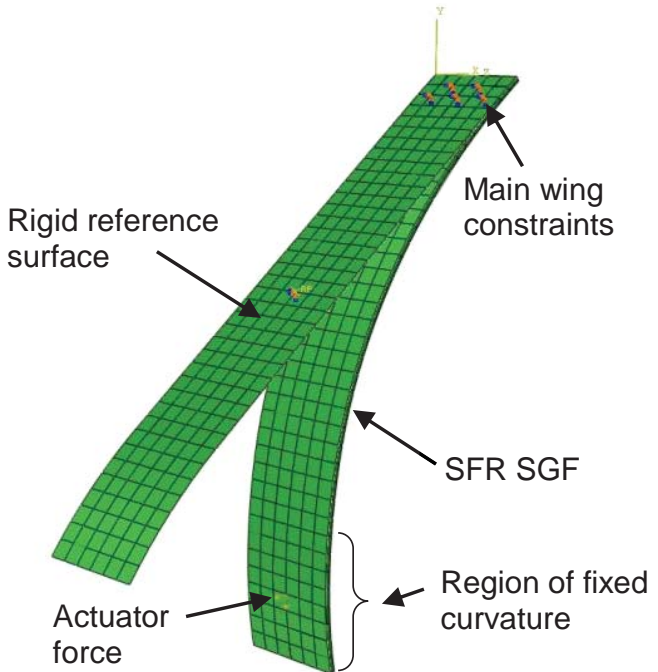

Figure 14. FEM for SFR SGF w/ actuator load and BCs.

( $\mathrm{E}=7 \mathrm{Msi}, \nu=0.33$ and $\rho=6.03 \mathrm{e}-4 \mathrm{lbf} \mathrm{s} \mathrm{s}^{2} \mathrm{in}^{4}$ ) were used along with the linear-elastic material model, a SGF thickness of 0.040 inches and the same main-wing constraints, representing a riveted connection. A normal force was defined at the actuator attachment location in the center of the RoFC (stringer-reinforcement), which was again assigned a modulus of $70 \mathrm{Msi}$. The finite element model corresponding to this analysis is shown in Figure 14.

As mentioned previously, the deflected shape of the SFR SGF due to the concentrated load near the tip would not naturally match the desired shape, which must be achieved via graded thickness, additional constraint, or other modifications. Additional constraint was imposed upon the SGF in the present analysis by introducing a rigid surface matching the desired deployed shape. The applied force was defined as the "follower" type in order to maintain its normal orientation and prevent introduction of tensile or compressive load in the SGF. Geometrically-nonlinear static analyses were performed with increasing actuator force until the SGF was observed to make contact with the rigid surface over its entire length. The logarithmic, longitudinal strain field on the outer (convex) surface corresponding to the 0.040 "-thick SFR SGF at full deployment is shown in Figure 15 . The graphic of the SGF is inverted in these figures to avoid the rigid surface obscuring the strain fringes. The spurious regions without strain data are due to minor contact penetration. It can be seen that the maximum strain was approximately $6600 \mu \varepsilon$ or $0.66 \%$, which again meets the limit for the linear-elastic material model.

The actuator force needed to fully deploy the SFR SGF to the desired shape was approximately $8 \mathrm{lbf}$, which was consistent with the SFD case as expected. The actuator force requirement was again reduced to $1 \mathrm{lbf}$ by reducing the SGF thickness to 0.020 inches. Alternatively, releasing the constraint on the deployed shape, i.e., by removing the rigid surface from the model, reduced the actuator requirement to approximately $2.5 \mathrm{lbf}$ for the 0.040 "-thick SFR SGF. However, this came at the expense of the deflected shape exceeding the desired profile by approximately 0.2 inches, as shown in Figure 16. Imposing the aerodynamic load on this configuration deflected it an additional $\sim 0.02$ inches, for a total of $\sim 0.22$ inches exceeding the desired shape.

The aerodynamic load and structural restoring force oppose one another in this case. The aerodynamic load again increases with increasing deployment, while the SFR SGF restoring force also increases in this case. Thus, the aerodynamic load assists the actuator in deployment and the SGF assists the actuator in retraction. The opposing effect reduces the actuator requirement, reduces the bias needed

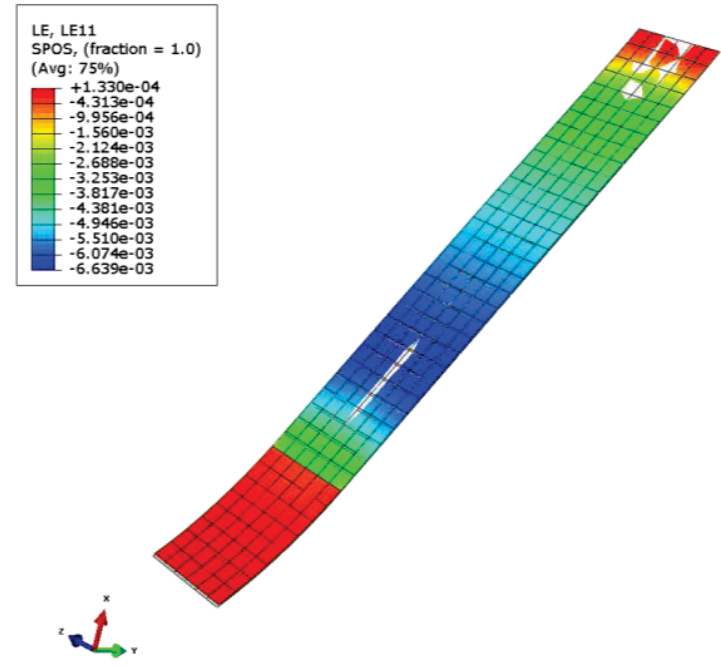

Figure 15. OML-surface strain due to SFR SGF deployment

to retract during anomalous or emergency conditions and results in a failsafe condition.

\section{Summary}

Airframe noise from high-lift systems on typical transport aircraft is a significant problem that is growing in importance. The leading-edge-slat component of conventional high-lift systems is a prominent source of airframe noise. Many noise reduction treatments have been proposed and studied, most notably slat-cove fillers and drooped leading edges. Limited noise-reduction efficacy of slat-cove-filler concepts and the inability of drooped-leading edge concepts to achieve high-lift equivalent to the baseline spurred continued investigation into alternatives. A new

American Institute of Aeronautics and Astronautics 
concept, termed the slat-gap filler, that can achieve noise-reduction equivalent to a drooped leading edge and high lift equivalent to the baseline was proposed and studied in this work.

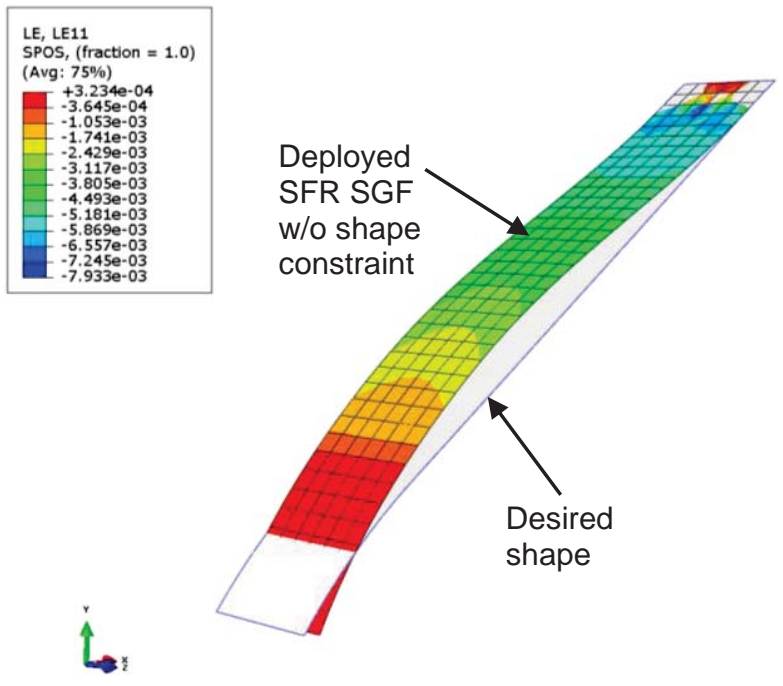

Figure 16. OML-surface strain and deflected shape w/o enforcing desired shape.

The slat-gap filler concept and its relation to other treatments was described in detail. The implementation approach entailed reconfiguring (deforming) a flexible overleaf of the stressed skin on the leading edge of the main wing to strategically and selectively close the slat gap. Requirements and constraints of the application were described along with the chosen slat-gap-filler implementation. A bench-top model was developed to study implementation feasibility and the parameter space. Estimates of deformation required for reconfiguration of the structure were on the order of $1 \%$. Although this strain level was thought to be only moderate, as compared to slat-cove filler concepts, it was well beyond the capability of conventional materials. Superelastic shape memory alloy materials were found to be ideal for the application.

Computational models were developed to help design the bench-top apparatus and to assess the relative merits of two slat-gap-filler implementation strategies, known as the stress-free-deployed and the stress-free-retracted concepts. It was found that a reconfigurable skin as thin as 0.020 inches could sustain the static aerodynamic load with acceptable deflection. The actuator force required for either slat-gap-filler concept was determined to be quite low at $1.3 \mathrm{lbf}$ per inch of span for the 0.020 -inch thickness. The aerodynamic load and structural restoring force combine for the stress-free-deployed case and oppose one another for the stress-free-retracted concept. This difference proved to be critical in the feasibility of implementation. The opposing effect for the SFR SGF reduced the actuator and emergency bias requirements relative to the SFD case. The SFR case was also found to be a failsafe configuration whereas the SFD was not.

\section{Future Work}

Work that remains to be completed includes making quantitative measurements of the actuator authority required to articulate various slat-gap filler prototypes as well as the deformation field induced in each case. Higher-fidelity computational models will be developed to include the mechanization and will be validated with the experimental measurements from the bench-top apparatus. The validated computational models will then be used to study 3D effects such as wing sweep and taper and dynamic fluid structure interaction.

\section{Acknowledgments}

David Lockard, Medhi Khorrami and Craig Streett (NASA LaRC) provided valuable guidance on requirements of the application and on aerodynamics/aeroacoustics in general and they were valuable collaborators on concept development. The assistance of David Lockard and Veer Vatsa (NASA LaRC) in providing aerodynamic load data is greatly appreciated. The collaboration and assistance of Reggie T. Kidd, M. Joseph McKenney and Raymond Atherly (Analytical Mech. Assoc.) in design of the bench-top apparatus is also greatly appreciated. The assistance of Johnnie West and George Hilton (NASA LaRC) in fabrication, assembly and modification of the bench-top assemblies is also gratefully acknowledged. Joe Kain and Carlos Pimental (Johnson-Matthey, Inc.) ably fabricated the shape memory alloy flexures used in this study. Support from NASA's Fundamental Aeronautics, Fixed-Wing Project is also gratefully acknowledged.

\section{References}

${ }^{1}$ Mau, K. and Dobrzynski, W., Airbus Deutschland GmbH, Hamburg, DE, Deutsches Zentrum Fuer Luft-und Raumfahrt e. V., Cologne, DE, "Flexible airflow separator to reduce aerodynamic noise generated by a leading edge slat of an aircraft wing," U.S. Patent No. 6,789,769, 14 September 2004.

${ }^{2}$ Khorrami, M. D., Berkman, M. E., and Choudhari, M., "Unsteady flow computations of a slat with a blunt trailing edge," AIAA Journal, Vol. 38, No. 11, 2000, pp. 2050-2058.

American Institute of Aeronautics and Astronautics 
${ }^{3}$ Singer, B. A., Lockard, D. P., and Brentner, K. S., "Computational Aeroacoustic Analysis of Slat Trailing-Edge Flow," AIAA Journal, Vol. 38, No. 9, 2000, pp. 1558-1564.

${ }^{4}$ Khorrami, M. R., Singer, B. A., and Berkman, M. E., "Time-accurate Simulations and Acoustic Analysis of Slat Free Shear Layer," AIAA Journal, Vol. 40, No. 7, 2002, pp. 1284-1291.

${ }^{5}$ Khorrami, M. R., Singer, B. A., and Lockard, D. P., "Time-accurate Simulations and Acoustic Analysis of Slat Free Shear Layer: Part II," 8 $8^{\text {th }}$ AIAA/CEAS Aeroacoustics Conference \& Exhibit, AIAA Paper 2002-2579, 2002.

${ }^{6}$ Choudhari, M., Khorrami, M. R., Lockard, D. P., Atkins, H. L., and Lilley, G. M., "Slat Cove Noise Modeling: A Posteriori Analysis of Unsteady RANS Simulations," 8 $8^{\text {th }}$ AIAA/CEAS Aeroacoustics Conference \& Exhibit, AIAA Paper 2002-2468, 2002.

${ }^{7}$ Chow, L.C., Mau, K., and Remy, H., "Landing Gears and High Lift Devices Airframe Noise Research," $8^{\text {th }}$ AIAA/CEAS Aeroacoustics Conference \& Exhibit, AIAA Paper 2002-2408, 2002.

${ }^{8}$ Khorrami, M. R. and Lockard, D. P., "Effects of Geometric Details on Slat Noise Generation and Propagation," $12^{\text {th }}$ AIAA/CEAS Aeroacoustics Conference \& Exhibit, AIAA Paper 2006-2664, 2006.

${ }^{9}$ Gleine, W., Mau, K., and Carl, U., Airbus Deutschland GmbH, Hamburg, DE, “Aerodynamic Noise Reducing Structure for Aircraft Wing Slats," US Patent No. US 6,394,396 B2, 28 May 2002.

${ }^{10}$ Streett, C. L., Casper, J. H., Lockard, D. P., Khorrami, M. R., Stoker, R. W., Elkoby, R., Wenneman, W. F., and Underbrink, J. R., "Aerodynamic Noise Reduction for High-Lift Devices on a Swept Wing Model," $44^{\text {th }}$ AIAA Aerospace Sciences Meeting and Exhibit, AIAA Paper 2006-212, 2006.

${ }^{11}$ Horne, W. C., James, K. D., Arledge, T.K., Soderman, P.T., Burnside, N., and Jaeger, S.M., "Measurements of 26\%-scale 777 Airframe Noise in the NASA Ames 40- by 80 Foot Wind Tunnel," $11^{\text {th }}$ AIAA/CEAS Aeroacoustics Conference \& Exhibit, AIAA Paper 2005-2810, 2005.

${ }^{12}$ Imamura, T., Ura, H., Yokokawa, Y., Enomoto, S., Yamamoto, K., and Hirai, T., "Designing of Slat Cove Filler as a Noise Reduction Device for Leading-edge Slat," 13 ${ }^{\text {th }}$ AIAA/CEAS Aeroacoustics Conference \& Exhibit, AIAA Paper 2007-3473, 2007.

${ }^{13}$ Imamura, T., Ura, H., Yokokawa, Y., "Numerical and Experimental Research of Low-Noise Slat using Simplified High-Lift Model," 14 $4^{\text {th }}$ AIAA/CEAS Aeroacoustics Conference \& Exhibit, AIAA Paper 2008-2918, 2008.

${ }^{14}$ Qureshi, H., Hamdani, H. R., and Parvez, K., "Effects on Dynamic Stall on Cambered Airfoil with Drooping Leading Edge Control," 44 ${ }^{\text {th }}$ AIAA Aerospace Sciences Meeting \& Exhibit, AIAA Paper 2006-1064, 2006.

${ }^{15}$ Hileman, J. I., Reynolds, T. G., de la Rosa Blanco, E., Law, T. R., and Thomas, S., "Development of Approach Procedures for Silent Aircraft," 45 $5^{\text {th }}$ AIAA Aerosciences Meeting \& Exhibit, AIAA Paper 2007-451, 2007.

${ }^{16}$ Khodadoust, A. and Washburn, A., "Active Control of Flow Separation on a High-Lift System with Slotted Flap at High Reynolds Number," 25 th AIAA Applied Aerodynamics Conference, AIAA Paper 2007-4424, 2007.

${ }^{17}$ Maldar, A., Arokkiaswamy, A., Gemson, R. M. O., and Sanal Kumar, V. R., "Aerodynamic Sound Reduction for Silent Aircraft," 46 ${ }^{\text {th }}$ AIAA Aerosciences Meeting \& Exhibit, AIAA Paper 2008-150, 2008.

${ }^{18}$ Bain, J. J., Sankar, L. N., Prasad, J. V. R., Bauchau, O. A., Peters, D. A., and He, C., "Computational Modeling of VariableDroop Leading Edge in Forward Flight," Journal of Aircraft, Vol. 46, No. 2, 2009, pp. 617-626.

${ }^{19}$ Hall, C. A., Schwartz, E., and Hileman, J. I., "Assessment of Technologies for the Silent Aircraft Initiative," Journal of Propulsion and Power, Vol. 25, No. 6, December 2009, pp. 1153-1162.

${ }^{20}$ Turner, T. L.; Kidd, R. T.; Hartl, D. J.; and Scholten, W. D.: "Development of a SMA-Based, Slat-Cove Filler for Reduction of Aeroacoustic Noise Associated with Transport-Class Aircraft Wings," Proc. ASME 2013 Conf. on Smart Matl., Adapt. Struct. and Intell. Sys., SMASIS2013-3100, 2013.

${ }^{21}$ Scholten, W. D.; Hartl, D. J.; and Turner, T. L.: "Analysis-Driven Design Optimization of a SMA-Based Slat-Cove Filler for Aeroacoustic Noise Reduction,” Proc. ASME 2013 Conf. on Smart Matl., Adapt. Struct. and Intell. Sys., SMASIS2013-3104, 2013.

${ }^{22}$ Guo, Y., Pitera, D. M., Pitt, D. M., Shmilovich, A., and White, E. V., "Multi-Objective Leading Edge Concepts," NASA Contract NAS1-NNL04AA11B, Task NNL08AD73T, Final Report, June 2009.

${ }^{23}$ Wang, D., Bartley-Cho, J., Kjerstad, K., Kwon, H., Rahrig, K., Schein, D., Ho, W., and Speer, S., "Multi-Objective Leading Edge Concepts," NASA Contract NAS1-NNL04AA13B, Task NNL08AD75T, Final Report, June 2009.

${ }^{24}$ Lagoudas, D.C. (Editor), Shape Memory Alloys: Modeling and Engineering Applications, Springer Science+Business Media, LLC, New York, NY, 2008.

American Institute of Aeronautics and Astronautics 